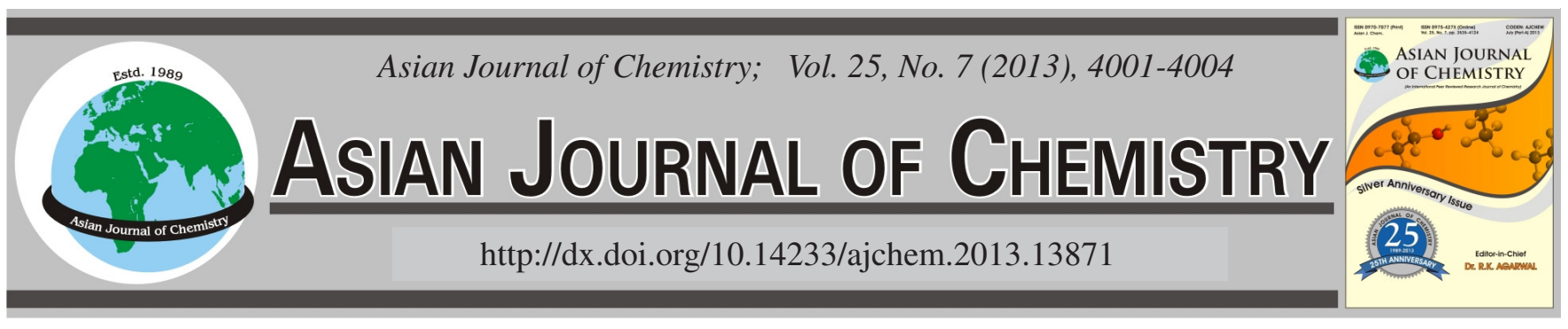

\title{
Chromium(VI) Catalyzed Oxidation of Primary Alcohol by Polymer Supported Reagent: A Kinetic and Mechanistic Approach
}

VILAS Y. SONAWANE

Department of Chemistry, B. Raghunath Arts, Commerce and Science College, Parbhani-434 401, India

Corresponding author: E-mail: sonawane_vy@ rediffmail.com

\begin{abstract}
The kinetic of chromium(VI) catalyzed oxidation of 1-phenyl ethanol has been studied by the rate of disappearance of [Cr(VI)]. The reaction is zero order with respect to $[\mathrm{Cr}(\mathrm{VI})]$. The reagent supported on anion exchange resin was found to be more efficient in the oxidation reaction. The reagent is very easily separated from the reaction mixture and can be manually removed from the reaction mixture, which remains clear during and after the reaction. The kinetic of oxidation of 1-phenylethanol with chromic acid supported on anion exchange resin like Amberjet-4400 $\left[\mathrm{Cl}^{-}\right]$in 1,4-dioxane has been studied. The reaction is found to be of zero order each in concentration of alcohol and oxidant. The reaction constants involved in the mechanism and the activation parameters have been calculated. There is a good agreement between observed and calculated rate constants under different experimental conditions. Acetophenone was detected as end product.
\end{abstract}

Key Words: Kinetics, 1-Phenyl ethanol, Chromium(VI) Polymer-supported chromic acid, Thermodynamic parameters.

\section{INTRODUCTION}

Transition metals in the higher oxidation state can be stabilized by chelating with suitable complex agent ${ }^{1-4}$. The kinetics and mechanism of oxidation of chromium(VI) has been well studied, chromic acid being one of the most versatile available oxidizing agents, reacting with diverse substrates. Now a day the development of newer chromium(VI) reagents ${ }^{5-11}$ for the oxidation of organic substrates continues to be of interest. Chromium is one of the most widely distributed heavy metals in the earth's crust. It is normally found into oxidation states i.e. $\mathrm{Cr}(\mathrm{III})$ and $\mathrm{Cr}(\mathrm{V})$. Chromium is required in small quantities as an essential trace metal. Most of the biological tissues contain $\mathrm{Cr}$ (III) which is usually non toxic, where as $\mathrm{Cr}(\mathrm{VI})$ is a highly toxic for the metal to the organism ${ }^{12}$. The selective oxidation of primary alcohols and secondary alcohols into their corresponding aldehydes (or carboxylic acids) and ketones is one of the important transformations in modern organic synthesis.

In the present investigation, we now report the oxidation of 1-phenyl ethanol by polymer-supported chromic acid. Amberjet-4400 $\left[\mathrm{Cl}^{-}\right]$is the strong anion exchange resin is supported on chromium(VI) oxide and used as an oxidant.

\section{EXPERIMENTAL}

All the reagents used were of highest purity available. Aqueous solution of chromic acid was prepared always afresh and standardized iodimetrically.
Preparation of supported oxidizing agent: The supported oxidizing agent was prepared by reported method ${ }^{13-15}$. The chloride form of Amberjet-4400 $\left[\mathrm{Cl}^{-}\right]$[a macro reticular anion exchange resin] containing a quaternary ammonium group [10 $\times 10^{-3} \mathrm{~kg}$ ] was stirred with a saturated solution of chromium trioxide $\left[5 \times 10^{-3} \mathrm{dm}^{3}\right]$ in water $\left[30 \times 10^{-3} \mathrm{dm}^{3}\right]$ for $0.5 \mathrm{~h}$ at room temperature using a magnetic stirrer. The chloride ion was readily displaced and $\mathrm{HCrO}_{4}^{-}$form of resin was obtained in $0.5 \mathrm{~h}$. The resin was successively rinsed with water, acetone and THF and finally dried in vaccum at $323 \mathrm{~K}$ for $5 \mathrm{~h}$. The dried form of the resin was stored and used throughout the kinetic study.

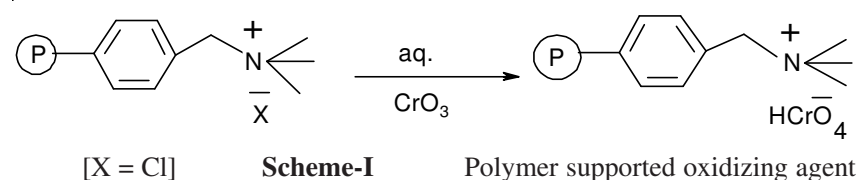

Determination of the capacity of chromate form of the polymeric reagent: The capacity of the chromate form of Amberjet-4400 $\left[\mathrm{Cl}^{-}\right]$polymeric reagent was determined by iodometrically. The capacity of the chromate form of resin was $1.65 \mathrm{eq} / \mathrm{L}$ and used for kinetic study throughout work. The loading was also determined by elemental nitrogen analysis and was found to be $1.69 \mathrm{eq} / \mathrm{L}$.

All reagents used were of Analytical grade and all solutions were prepared with double distilled water. 
Method of kinetics: The reaction mixture for the kinetic run was prepared by mixing alcohol, oxidant and solvent. The reaction was carried out either constant stirring using magnetic stirrer and at a constant temperature $318 \pm 1 \mathrm{~K}$. At different time interval, the reaction mixture was withdrawn using a micropipette. The aliquot thus withdrawn was taken in a stoppered test tube containing $5 \times 10^{-3} \mathrm{dm}^{3}$ of 1,4-dioxane and subjected to spectral analysis. The absorbance of the product formed was measured using SL 159 UV-visible spectrophotometer. Duplicate kinetic runs showed that the rate constants were reproducible to within $\pm 1 \%$.

Induced polymerization test: Mixing oxidant, alcohol and solvent at $318 \mathrm{~K}$ with continuous stirring did initiation of reaction. After $0.5 \mathrm{~h}$, the reaction mixture was withdrawn in a test tube and acrylonitrile was added. The mixture after dilution with distilled water formed a copious precipitate. The precipitate formed, due to polymerization of acrylonitrile, indicates formation of a free radical species in the reaction ${ }^{16}$. It was also confirmed by ESR spectral analysis as well as on diluting the reaction mixture with acidified methanol.

Product analysis: The oxidation of 1-phenyl ethanol leads to the formation of acetophenone. The product formed was analyzed by their 2,4-dinitrophenylhydrazone derivatives. The precipitated 2,4-dinitrophenylhydrazone (DNP) was filtered off, the product is then vacuum dried, weighed and recrystallized from ethanol. The yield of dinitrophenylhydrazone recrystallization with the DNP of acetophenone was $86 \%$. The product also identified either by comparison with authentic samples or by UV, FT-IR spectral and elemental analysis. The IR spectra were recorded on a Jasco FT-IR spectrophotometer using $\mathrm{KBr}$ pellets. The melting point of 2,4-dinitrophenylhydrazone derivative of 1-phenyl ethanol is $237^{\circ} \mathrm{C}$ [510 K].

$$
\text { UV spectrum - } \lambda_{\max } 246 \mathrm{~nm}
$$

IR data: A sharp band at $1683 \mathrm{~cm}^{-1}$ for $-\mathrm{C}=\mathrm{O}$ stretching mode, $1585 \mathrm{~cm}^{-1}$ aromatic. (-C $\left.=\mathrm{C}-\right), 3063 \mathrm{~cm}^{-1}$ (-C-H stretch).

\section{RESULTS AND DISCUSSION}

Effect of varying weights of oxidant: The order with respect to weights oxidant is zero, as the plots of absorbance against time were linear in all runs and observed rate constant are fairly constant between 50 to $80 \times 10^{-6} \mathrm{~kg}$ of oxidant at constant concentration of solvent (1,4-dioxane, $\left.5 \times 10^{-3} \mathrm{dm}^{3}\right)$ and 1-phenylethanol $\left(12.3 \times 10^{-3} \mathrm{~mol} / \mathrm{dm}^{-3}\right)$, the effect of varying weights of oxidant on zero order rate constant as shown in Table-1.

\begin{tabular}{|c|c|c|c|c|}
\hline \multicolumn{5}{|c|}{$\begin{array}{c}\text { TABLE-1 } \\
\text { EFFECT OF VARYING WEIGHTS OF OXIDANT } \\
\text { ON REACTION RATE AT } 318 \mathrm{~K}\end{array}$} \\
\hline Rate constant $\rightarrow$ & & $\mathrm{k} \times 10^{-}$ & $\mathrm{dm}^{-3} \mathrm{~s}$ & \\
\hline Oxidant $\times 10^{-6} \mathrm{~kg} \rightarrow$ & 50 & 60 & 70 & 80 \\
\hline Amberjet-4400 [ $\left.\mathrm{Cl}^{-}\right]$ & 1.85 & 1.92 & 1095 & 1.99 \\
\hline
\end{tabular}

Effect of varying concentrations of 1-phenyl ethanol: At a varying concentration of 1-phenylethanol [8.20 to $20.4 \times$ $\left.10^{-3} \mathrm{~mol} / \mathrm{dm}^{3}\right]$, constant weights of oxidant $\left[70 \times 10^{-6} \mathrm{~kg}\right]$ and constant concentration of solvent [1,4-dioxane, $\left.5 \times 10^{-3} \mathrm{dm}^{3}\right]$, zero order rate constant (Table-2) was found.

TABLE-2
EFFECT OF VARYING CONCENTRATIONS
OF 1- PHENYL ETHANOL

Effect of varying dielectric permittivity of the medium on the reaction rate: It was found that as the dielectric constant of the medium increased, this including $\mathrm{r}^{*}<\mathrm{r}$ [where $r^{*}$ and $r$ refer to the radii of the reactant species and activated complex respectively] at constant concentration of 1-phenyl ethanol $\left[12.3 \times 10^{-3} \mathrm{~mol} / \mathrm{dm}^{3}\right]$ and constant concentration of oxidant $\left[70 \times 10^{-6} \mathrm{Kg}\right]$, solvent $\left[5 \times 10^{-3} \mathrm{dm}^{3}\right]$ as shown in Table-3.

TABLE-3

EFFECT OF VARYING DIELECTRIC PERMITIVITY

\begin{tabular}{lcccc}
\hline Rate constant $\rightarrow$ & \multicolumn{4}{c}{$\mathrm{k} \times 10^{-4} \mathrm{~mol} \mathrm{dm}^{-3} \mathrm{~s}^{-1}$} \\
\hline Solvent $\left[5 \times 10^{-3} \mathrm{dm}^{3}\right] \rightarrow$ & $\mathrm{C}_{6} \mathrm{H}_{12}$ & $\mathrm{CCl}_{4}$ & $1,4-$ dioxane & $\mathrm{CHCl}_{3}$ \\
Dielectric constant $\rightarrow$ & 2.00 & 2.17 & 2.28 & 4.81 \\
Amberjet- $4400\left[\mathrm{Cl}^{-}\right]$ & 1.25 & 1.59 & 2.46 & 2.86 \\
\hline
\end{tabular}

Effect of varying temperature: The reaction was carried out at four different temperatures under otherwise similar reaction conditions to study the effect of temperatures on the rate of reaction. It was observed that, the rate of reaction increased with an increase in the temperature. [Table-4]. The activation parameters like energy of activation $\left[\mathrm{E}_{\mathrm{a}}\right]$, enthalpy of activation $\left[\Delta \mathrm{H}^{\#}\right]$, entropy of activation $\left[\Delta \mathrm{S}^{\#}\right]$ free energy of activation $\left[\Delta \mathrm{G}^{\#}\right]$ the high positive values of free energy of activation indicates that the transition state is highly solved and frequency factor [A] were calculated by determining values of $\mathrm{k}$ at different temperatures [Table-5].

\begin{tabular}{|c|c|c|c|c|}
\hline \multicolumn{5}{|c|}{$\begin{array}{c}\text { TABLE-4 } \\
\text { EFFECT OF VARYING TEMPERATURE }\end{array}$} \\
\hline Rate constant $\rightarrow$ & \multicolumn{4}{|c|}{$\mathrm{k} \times 10^{-4} \mathrm{~mol} \mathrm{dm}^{-3} \mathrm{~s}^{-1}$} \\
\hline Temperature $\mathrm{K} \rightarrow$ & 313 & 318 & 323 & 328 \\
\hline Amberjet- $4400\left[\mathrm{Cl}^{-}\right]$ & 1.95 & 2.12 & 2.43 & 2.78 \\
\hline \multicolumn{5}{|c|}{$\begin{array}{c}\text { TABLE-5 } \\
\text { ACTIVATION PARAMETERS }\end{array}$} \\
\hline \multicolumn{3}{|c|}{ Energy of activation [Ea] $\mathrm{KJ} \mathrm{mol}^{-1}$} & \multicolumn{2}{|c|}{$85 \pm 4$} \\
\hline \multicolumn{3}{|c|}{ Enthalpy of activation $\left[\Delta \mathrm{H}^{\#}\right] \mathrm{KJ} \mathrm{mol}^{-1}$} & \multicolumn{2}{|c|}{$65 \pm 3$} \\
\hline \multicolumn{3}{|c|}{ Entropy of activation $\left[\Delta S^{\#}\right] \mathrm{JK} \mathrm{mol}^{-1}$} & \multicolumn{2}{|c|}{$-75 \pm 2$} \\
\hline \multicolumn{3}{|c|}{ Free energy of activation $\left[\Delta \mathrm{G}^{\#}\right] \mathrm{KJ} \mathrm{mol}^{-1}$} & \multicolumn{2}{|c|}{$302 \pm 2$} \\
\hline \multicolumn{3}{|c|}{ Frequency factor $[\mathrm{A}] \times 10^{-5} \mathrm{~s}^{-1}$} & \multicolumn{2}{|c|}{$4 \pm 0.5$} \\
\hline
\end{tabular}

Effect of repeated use of supported oxidizing agent: The resin was filtered after the reaction and washed with 0.1 $\mathrm{M} \mathrm{HCl}$ and $0.2 \mathrm{M} \mathrm{NaOH}$ successively to remove $\mathrm{CrO}_{2}$ deposition on the resin. The resin was then regenerated by stirring with chromic acid, followed by washing with water methanol and drying in vacuum at $333 \mathrm{~K}$ for $5 \mathrm{~h}$.

Several sets of experiments with various weights of oxidant, concentration of 1-phenyl ethanol and change in solvent were carried out. The reaction was found to be zero order. The proposed path for the reaction of chromium(IV) then makes 
possible a different mechanism for oxidation of alcohols. According to Westheimer and Watanable ${ }^{16}$ subsequent steps must involve chromium(IV) as shown in Schemes (II) and (III).

$$
\begin{gathered}
\text { Scheme (II) } \\
\mathrm{Cr}^{\mathrm{IV}}+\mathrm{Cr}^{\mathrm{VI}} \rightarrow 2 \mathrm{Cr}^{\mathrm{V}} \\
\mathrm{Cr}^{\mathrm{V}}+\mathrm{R}_{2} \mathrm{CHOH} \rightarrow \mathrm{R}_{2} \mathrm{C}=\mathrm{O}+\mathrm{Cr}^{\mathrm{III}}+2 \mathrm{H}^{+} \\
\text {Scheme }(\mathrm{III}) \\
2 \mathrm{Cr}^{\mathrm{V}} \rightarrow \mathrm{Cr}^{\mathrm{III}}+\mathrm{Cr}^{\mathrm{V}} \\
\mathrm{Cr}^{\mathrm{V}}+\mathrm{Red} \rightarrow \mathrm{Cr}^{\mathrm{III}}+\text { oxi }
\end{gathered}
$$

Westheimer then proposed that the oxidation of secondary alcohols proceeded via acid chromate ester intermediates.

$$
\begin{gathered}
\mathrm{R}_{2} \mathrm{CHOH}+\mathrm{HCrO}_{4}+\mathrm{H}^{+} \rightarrow \mathrm{R}_{2} \mathrm{CHOCrO}_{3} \mathrm{H}+\mathrm{H}_{2} \mathrm{O} \\
\mathrm{R}_{2} \mathrm{CHOCrO}_{3} \mathrm{H}+\mathrm{H}^{+} \rightarrow \mathrm{R}_{2} \mathrm{CHOCrO}_{3} \mathrm{H}_{2}^{+} \\
\mathrm{R}_{2} \mathrm{CHOCrO}_{3} \mathrm{H} \rightarrow \mathrm{R}_{2} \mathrm{C}=\mathrm{O}+\mathrm{Cr}^{\mathrm{IV}} \\
\mathrm{R}_{2} \mathrm{CHOCrO}_{3} \mathrm{H}_{2}^{+} \rightarrow \mathrm{R}_{2} \mathrm{C}=\mathrm{O}+\mathrm{Cr}^{\mathrm{IV}}
\end{gathered}
$$

If the oxidant supported on polymer, which has certain advantages over homogeneous reaction, the intermediate chromium(IV) will further oxidize another molecule of alcohol to form a free radical species. Thus based on experimental results, obtained for the oxidation of 1-phenyl ethanol by polymer support, the reaction was found to be zero order. Initially $\mathrm{Cr}(\mathrm{VI})$ is reduced to $\mathrm{Cr}(\mathrm{IV})$. It is likely to react with another $\mathrm{Cr}(\mathrm{VI})$ to generate $\mathrm{Cr}(\mathrm{V})$ which is then reduced in a fast step to the ultimate product $\mathrm{Cr}(\mathrm{III})$. Such a sequence of reactions in $\mathrm{Cr}(\mathrm{VI})$ oxidation is well known ${ }^{17-19}$.

On the basis of above discussion and experimental results the following reaction scheme is proposed for $\mathrm{Cr}(\mathrm{VI})$ catalyzed oxidation of 1-phenyl ethanol. The mechanism is suggested in Scheme-IV and involves ester formation.

1) The polymer supported reagent reacts with a molecule of alcohol to form a chromate ester.
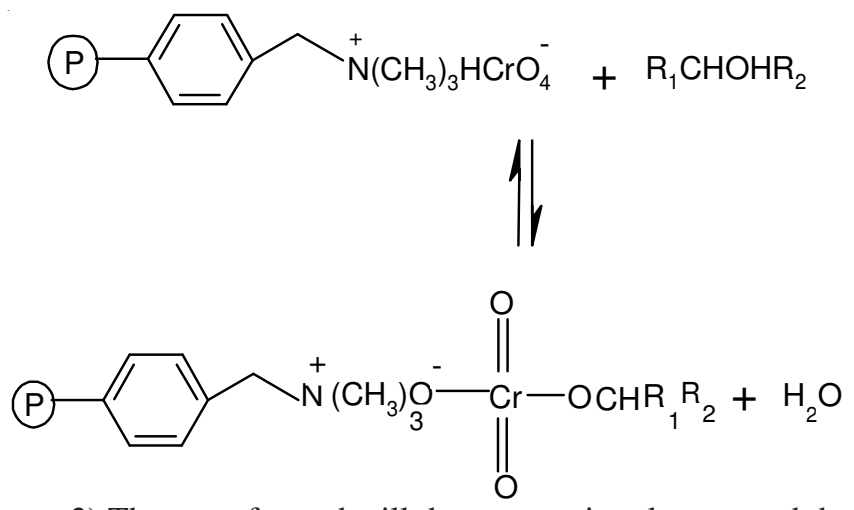

2) The ester formed will decompose into ketone and the intermediate chromium(IV) will be formed in the second and slow step.

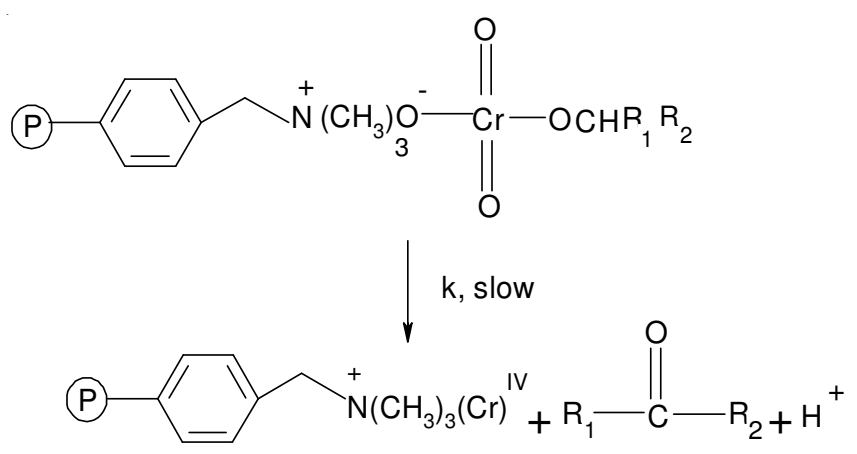

3) The intermediate chromium(IV) thus reacts with another alcohol molecule to produce a free radical species.

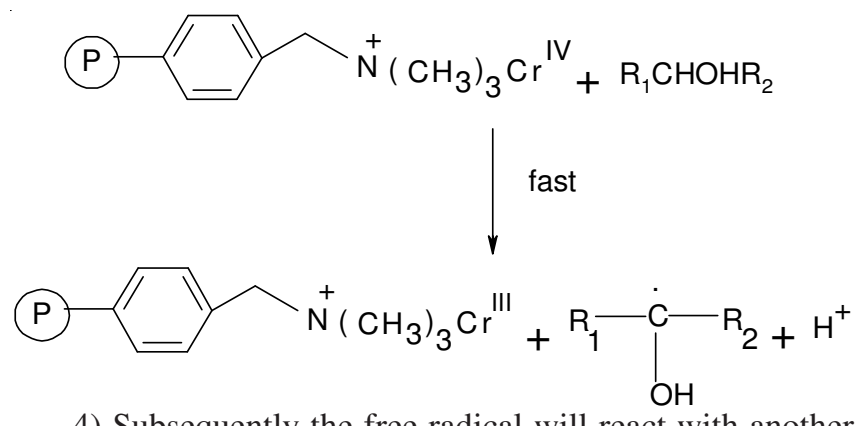

4) Subsequently the free radical will react with another oxidant site in the polymeric reagent in a fast step leading to the formation of chromium(V).

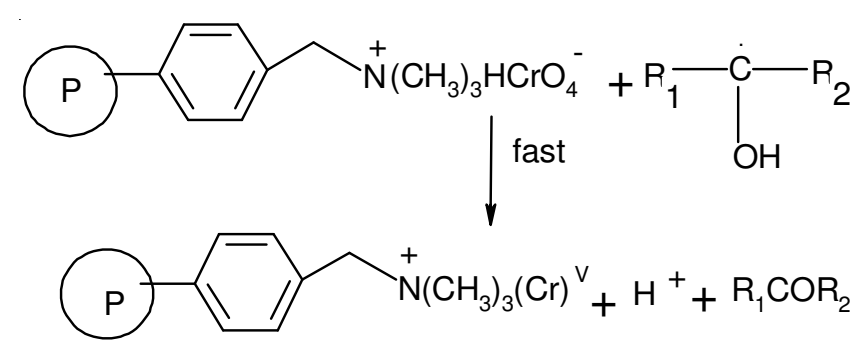

5) The intermediate chromium(V) in the last step reacts with 1-phenyl ethanol produce acetophenone. The test for formation of chromium(V) and (IV) by the characteristic induced oxidation of iodide ${ }^{12}$ and manganese(II) $)^{20}$ were not probably due to heterogeneity of the reaction mixture.
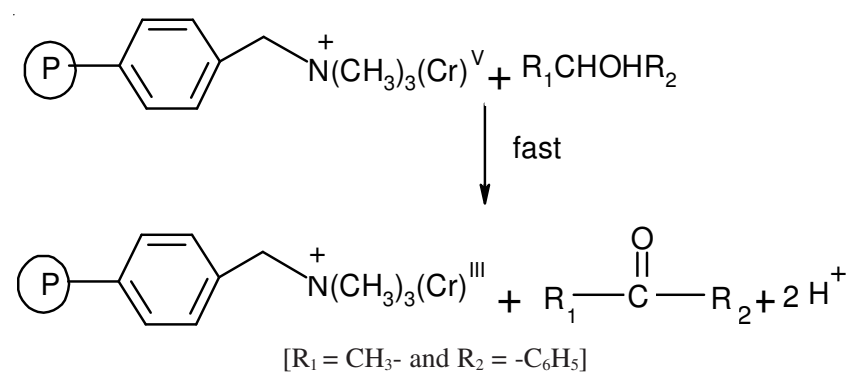

Scheme IV

\section{Conclusion}

The linearity of absorbance against time plots and constancy of the zero order rate constants indicate that the reaction neither depends on the polymeric reagents nor on the alcohol concentration. This anomalous nature of the reaction may be because of the fact that the oxidant is taken in the form of solid supported on polymer. Polymer supported oxidizing agent proved to be exclusively selective towards the oxidation of 1-phenyl ethanol, giving acetophenone as the only product.

According to Scheme-IV, a second order rate law is expected. But since the first step of ester formation occurs in solid phase and assuming that this equilibrium does not contribute to the rate of reaction. We obtained zero order dependence with rate constant $\mathrm{k}$ of the second slow step in which product acetophenone was obtained. Based on the experimental observations a probable mechanism is also suggested. 


\section{REFERENCES}

1. W.Y. Song, W.K. Li and C.P. Jia, Chem. J. Univ., 20, 1767 (1999).

2. W.Y. Song and H.M. Liu, Chin. J. Inorg. Chem., 16, 607 (2000).

3. J.H. Shan, J. Qian and T.Y. Zhai, Chin. J. Inorg. Chem., 19, 843 (2003).

4. S. Lakshmi and R. Renganathan, Int. J. Chem. Kinet., 28, 713 (1996).

5. E.J. Corey and G. Schmidt, Tetrahedron Lett., 20, 399 (1979).

6. M.N. Bhattacharjee, M.K. Choudhari, H.S. Dasgupta, N. Roy and D.T. Khating, Synthesis, 58 (1982).

7. E.J. Corey, E.P.M. Barette and P.A. Margrious, Tetrahedron Lett., 24, 5855 (1985).

8. F. Climinale, M. Camporeale, R. Mello, L. Troisi and R. Curci, J. Chem. Soc., Perkin Trans. II, 417 (1989).

9. G.G. Sharma and M.K. Mahanti, Bull. Soc. Chem. Fr. 128, 449 (1991).

10. K. Balasubramanian and V. Pratibha, Indian J. Chem., 25B, 326 (1986).
11. B. Narayana and T. Cherian, J. Braz. Chem. Soc., 16, 197 (2005).

12. A.J. Buglas and J.S. Waterhouse, J. Chem. Educ., 64, 3712 (1987)

13. G. Cainelli, G. Cardillio, M. Orena and S. Sardri, J. Am. Chem. Soc., 98, 6767 (1976).

14. T. Brunlet, C. Jouitteau and G. Gelhard, J. Org. Chem., 51, 4016 (1986).

15. W.A. Mosher, H. Clement and R.L. Hillard, J. Am. Chem. Soc., 29, 565 (1993).

16. W. Watanabe and F.H. Westheimer, J. Chem. Phys., 61, 17 (1979)

17. M.M. Salunke, D.G. Salunke, A.S. Kanade, R.B. Mane and P.P. Wadgaonkar, Synth. Commun., 20, 1143 (1990).

18. J. Matsuo, A. Kawana, K. Pudhon and T. Mukaiyama, Chem. Lett., 250 (2002)

19. R.O. Hutchins, N.R. Natale, W.J. Cook and J. Ohr, Tetrahedron Lett., 18, 4167 (1977).

20. J.H. Espenson, J. Am. Chem. Soc., 86, 5101 (1964). 